\title{
Editorial
}

\section{The IPCC and Antarctica}

Tow well is the scientific community doing on providing policy makers with evidence for climate 1 change and predictions for its future trends? The Intergovernmental Panel on Climate Change (IPCC) is one of the flagships of international scientific collaboration. Every five years, IPCC Working Group 1 compiles the state of the art in the science of climate change. The Third Assessment Report was presented in 2001, and writing of the Fourth Assessment Report began in the autumn of 2004. External, invited experts reviewed the initial draft last May and the final report will be made available to governments and public in late 2006. In September 2005 the first draft will even be published on the Internet for an eight-week external review period by anyone interested.

In contrast to the often-depressing sluggishness of political decision-making when it comes to mitigating climate change, the IPCC reports are a shining example of what international collaboration can achieve. The writing system adopted leads to a well-balanced and self-critical document that serves as a reference for all those interested in our changeable climate. Everybody can access it: the report is available through the Internet and summaries are translated into Arabic, Chinese, French, Russian and Spanish.

Since the previous IPCC report appeared in 2001, the role of the cryosphere has gained further importance in the discussion on climate change. In the upcoming assessment this will be reflected in a separate chapter dedicated to changes observed in snow, ice and frozen ground. Many Antarctic climate scientists have contributed to this chapter, because recent years have seen rapid and profound changes in the mass balance of the Antarctic ice sheet.

In 1978 Mercer predicted, in a paper in Nature, that the large Filchner and Ronne ice shelves were in danger of collapsing when atmospheric temperatures rose by 5-10 degrees. As it has no higher ground to retreat to, this would cause the marine-based West Antarctic ice sheet to collapse, increasing global sea level by about $5 \mathrm{~m}$. This prediction initiated a lively debate on the stability of the West Antarctic ice sheet. In the following decades the proposed buttressing effect of ice shelves on grounded ice was downplayed by glaciologists, but recent developments have forced them to review their models. Shortly after large parts of Larsen B ice shelf disintegrated in February 2002, the glaciers feeding it picked up speed, adding previously grounded ice to the oceans and raising global sea level. Similar imbalances have been reported from West Antarctic ice drainage basins. In retrospect, Mercer's prediction appears to have been eerily accurate.

Since the Third IPCC Assessment Report appeared in 2001, we have learned that there is a great deal that we do not know about how the giant Antarctic ice sheet reacts to changes in its environment. Atmospheric, oceanic and ice dynamics models alike have failed to predict the rapid changes that occurred, specifically the warming of the atmosphere and the oceans in the Antarctic Peninsula, the breakup of its ice shelves, the retreat of its floating ice tongues and the subsequent acceleration of its grounded glaciers. Comparing what we now know to the 2001 IPCC report, means that many statements concerning Antarctica will have to be revised or even reversed in the 2006 report: it appears that Antarctica can and will contribute to short-term sea level rise after all, contrary to the projections in 2001 . There even is a slight possibility that we are now witnessing the (partial) collapse of the West Antarctic ice sheet.

With respect to our ability to assess the contribution of the Antarctic ice sheet to future sea level rise, I fear that at present we are hardly able to keep up with documenting the observed changes, let alone predicting them.

MichiEL VAN DEN BROEKE 